\title{
ICT Experiences in Two Different Middle Eastern Universities
}

\author{
Abdallah Tubaishat \\ Zayed University, Abu Dhabi, \\ United Arab Emirates
}

Abdallah.Tubaishat@zu.ac.ae

\author{
Arif Bhatti \\ GIFT University, Chowk, \\ Gujranwala, Pakistan
}

drbhatti@gift.edu.pk

\author{
Eyas El-Qawasmeh \\ Jordan University of Science and Technology \\ Irbid, Jordan
}

eyas@just.edu.jo

\begin{abstract}
This research explores the impact of technology and culture on higher education in two Arab countries. In western countries where higher education is common, individuals regardless of their gender can meet, communicate, and collaborate at anytime at any place of their choice. This may not be true in Arab countries due to the social, cultural, and religious reasons. We argue that adoption of technology could provide a comparable learning environment to students in these countries. We present results of a case study based on surveys conducted in two universities, Jordan University of Science and Technology (JUST) in Jordan and Zayed University (ZU) in United Arab Emirates (UAE). Survey results show that adoption of technology has (a) improved the motivation and confidence level of students, (b) improved their communication and technical skills, (c) encouraged students to collaborate using Information and Communication Technology (ICT) tools, and (d) allowed students to be more independent. These improvements would not have been possible without technology in a gender-segregated society.
\end{abstract}

Keywords: Technology mediated learning environment, Social and cultural issues, Implementation of technology, Collaborative learning.

\section{Introduction}

The importance of higher education to gain prosperity and to develop human resources is under-

Material published as part of this publication, either on-line or in print, is copyrighted by the Informing Science Institute. Permission to make digital or paper copy of part or all of these works for personal or classroom use is granted without fee provided that the copies are not made or distributed for profit or commercial advantage AND that copies 1) bear this notice in full and 2) give the full citation on the first page. It is permissible to abstract these works so long as credit is given. To copy in all other cases or to republish or to post on a server or to redistribute to lists requires specific permission and payment of a fee. Contact Publisher@InformingScience.org to request redistribution permission. stood by under-developed countries. Three quarters of Arab universities were established in the last 25 years of the $20^{\text {th }}$ century (UNDP: Arab Human Development Report, 2003). Students in higher education require a very flexible environment to communicate and collaborate with their peers to accomplish tasks needed to succeed.

Social and cultural values of a society do impose different rules based on gen- 
der. Females in Arab society are usually subject to different sets of rules as compared to their male counterparts in the same society. These rules may severely limit the learning opportunities for females.

In western society, culture and social values do not impose any restriction on individuals based on their gender. Students in higher education regardless of their gender can meet, communicate, and collaborate at anytime at any place of their choice. In contrast, most Middle Eastern society is based on gender segregation that permits limited interaction between genders. Culture and social values in UAE and Saudi Arabia strictly enforce gender segregation, while countries such as Jordan and Lebanon are moderately liberal in this matter.

Advances in networking technologies and the Internet can have a significant impact on teaching and learning in higher education (Hodges, 2004; Muhlhauser \& Trompler, 2002; Smith \& Winking-Diaz, 2004). In a technology mediated learning environment, students and teachers use a wide range of ICT tools to communicate, collaborate and share resources; these tools provide anytime anywhere learning opportunities.

We begin by providing an overview of how ICT could be used to enhance traditional instructorled teaching to alleviate the impact of social and cultural values on higher education; to make the learning environment a place to pass information and knowledge from teacher to students, from students to teacher, and from students to students; and a place for creative thinking and learning. Next, we discuss education and learning environment in two Middle Eastern countries. We then discuss their ICT infrastructure and its impact on higher education. We conclude by presenting the findings from a case study based on surveys conducted at JUST in Jordan and at ZU in the UAE.

\section{Education and Learning Environment}

The UAE secondary schooling system remains very traditional with teacher-led classes where memorization is emphasized (Sanders \& Quirke, 2002). Students prefer all-knowing teachers who provide them answers to all questions. Only the UAE citizens can attend the public education system that has separate schools for boys and girls. The private education system is mainly for expatriots and is usually not segregated by gender at the school level. Some private higher education institutions have a co-education environment while others have separate arrangements for male and female students. The UAE provides free education for its citizens at all levels of education. United Nations (UN) statistics indicates that the UAE is among the most developed nations in educating female students (Information in the UAE, 2005). Each major center of population within the country has two colleges of technology, one for males, and another for females.

ZU was established for the national female population. The University has five colleges and most of the faculty members are western educated. Its faculty endeavor to provide students learning opportunities in an American style of teaching ensuring a very high quality of education. ZU's operations and policies reflect the impact of social and cultural values on higher education.

Women enroll in higher education more than men and their ratio is 6:2. In UAE, 20\% of the total work force is now women. Women have gained access to higher education, though they are still largely excluded from government decision making. More women are enrolled in higher education, partly because men tend to travel overseas to foreign universities (UNDP: POGAR, 2005). Adult male illiteracy exceeds female illiteracy (20\% to 21\% in 2002). National Admission and Placement Office (NAPO) indicated that $90 \%$ of females and $73 \%$ of males goes to federally funded higher colleges and universities (Women in the UAE, 2005). There are more female students than male students in UAE universities. In Higher Colleges of Technologies (HCT), there are $70 \%$ female students. In United Arab Emirates University (UAEU), there are 60\% female students. 
Education system in Jordan is co-education at kindergarten, college, and university levels. There are separate schools for boys and girls at elementary, primary, and secondary level. Few public schools have computer labs. Only $1.4 \%$ of public school teachers are computer literate. $60 \%$ of schools in Jordan are public (government owner/run) (World Economic Forum: Jordan Educational ICT pilot initiative, 2005). The development of Jordan's educational system can be described as dynamic, which means that it is evaluated and re-structured almost every year. Jordan has forged a comprehensive, high quality system to develop the human capital of its citizens. Currently almost one third of all Jordanians are enrolled in educational facilities. Women comprise a large percentage of Jordan's higher education attendees, accounting $66.6 \%$ of community college students, and $44.7 \%$ of the university populations.

In Jordan, there are public and private universities in all major centers of population. Most faculty members in science and engineering colleges are Jordanians who are western educated. The education system is more flexible and students usually improve their critical thinking skills in secondary schooling. Each student enrolled in higher education system must study two courses where one of them is computer skills course and the other is a programming course. This is regardless of the major of the student.

The Table 1 shows some educational facts about female education in Jordan and UAE (Technology and Equity, 2005).

Table 1. Educational and learning environment for females in Jordan vs. UAE

\begin{tabular}{|l|l|l|}
\hline & Jordan & UAE \\
\hline Female Adult Literacy & $84.4 \%$ & $76.8 \%$ \\
\hline Female Secondary School Enrollment & $55 \%$ & $79.9 \%$ \\
\hline Female Tertiary Students & $42 \%$ & $72 \%$ \\
\hline Female Tertiary Students in Natural Sciences & $35.5 \%$ & $42.3 \%$ \\
\hline
\end{tabular}

JUST consists of eleven colleges, including 55 academic departments offering 52 undergraduate programs, and 95 graduate programs. It is considered a large university with an enrollment of approximately 16,000 students. It has highly qualified staff members in diverse fields of knowledge. All academic programs are open to Jordanians and students from other Arab countries resulting in a culturally diverse environment. Some students come from moderately liberal cultures such as Syria, and Lebanon, while others come from more conservative cultures such as Saudi Arabia and Oman. All courses use English as the language of instructions (JUST Website, 2005).

\section{Culture and Higher Education}

In their paper "Toward a Theory Based Measurement of Culture” Straub, Loch, Evaristo, Karahanna, and Srite (2002) argued that in IS research, the culture of subjects and respondents is problematic because it is typically an overly simplistic categorization. IS research nearly always assumes that an individual living in a particular place and time belongs to a single "culture". This may explain why cross cultural research has been so extremely difficult to conduct!"

Most social and cultural values in Gulf society do not allow free mixing and interaction of members of opposite genders. A strong influence of these values on students, student teacher interaction and in university policies is visible in day-to-day activities at ZU and other public universities in UAE. 
ZU policy requires students to be on-campus during the normal operating hours. Students are not allowed to be on-campus after these hours. An electronic check-in and check-out system is used to ensure that students remain on-campus once they arrive. Students are not allowed to leave the campus without their family's permission. Attendance is required during each teaching session to ensure that students participate in class activities. During off-campus educational activities, students must be accompanied by chaperones. Normal working hours are 8:00 to 5:00 and students are not allowed to be on campus outside of this period for cultural and social reasons.

Cultural and social values in Jordan are moderately liberal. Unlike many other Arab countries, in Jordan there is a very small disparity in primary school attendance rates between urban and rural areas. Higher education institutions have co-education environment. The university environment in Jordan provides students regardless of their gender, significantly more opportunities to meet, communicate and collaborate. In Jordan, women participate in the work force in most jobs (e.g. military, nursing, technology). Women can travel freely after 18 years of age, which is not true in UAE. It is also safe to say that using technology in Jordanian society is easier than UAE due to the fact that the country is relatively liberal.

\section{Technology Infrastructure at ZU and JUST}

Advances in networking technologies and the Internet can have a significant impact on teaching and learning in higher education (Hodges, 2004; Muhlhauser \& Trompler, 2002; Smith \& Winking-Diaz, 2004). In our opinion, universities in the UAE have significantly better technology infrastructure than universities in Jordan. In UAE, students have more access to technology but they are less effective in using technology. For social and political reasons, many Internet sites are banned in UAE; and all home and Internet cafes traffic goes through a proxy.

ZU has an excellent technology infrastructure. ZU campuses are fully networked and allow students to connect to the University network and Internet from anywhere on campus. Each student is required to purchase a very recent laptop for use while on campus. Each faculty member receives a laptop with a three-year replacement schedule.

Students have a wealth of technology available to assist them in the learning process. Actually, $\mathrm{ZU}$ is known as the laptop university in this region. For the College of Information Systems, students having their own laptop loaded with software used in the courses help them to complete their work independently without coming to campus during after hours. The College of Information Systems has an independent network infrastructure for teaching and research, in addition to the University network. This infrastructure allows students to login remotely into Linux servers to use tools needed for programming languages, databases, and web development related courses. Students can also use Linux-based communication tools to collaborate with each other and with instructors. ZU students can access their university email accounts and Blackboard, a learning management system, from anywhere at anytime using a web client. Students have to be on campus to access all other computing and non-computing resources.

In Jordan, students have less access to technology but they are efficient in the use of it. The Internet is not considered as a threat to local culture, morals or religious sensibilities in general (Straub et al., 2002). Internet cafes and homes are not proctored by government and therefore there is free access to any Internet source. Introducing a new technology is easier to adopt, as the society is more liberal.

The Table 2 shows some technology facts about the two countries (UNDP: POGAR, 2005). 
Table 2. Technology facts in Jordan vs. UAE

\begin{tabular}{|l|l|l|}
\hline & Jordan & UAE \\
\hline Telephone mainlines & $127 / 1000$ & $291 / 1000$ \\
\hline Cellular mobile subscribers & $229 / 1000$ & $647 / 1000$ \\
\hline Internet users & $57 / 1000$ & $313 / 1000$ \\
\hline
\end{tabular}

In Jordan, JUST laboratories are fully equipped with the latest hardware and software programs. The college of Computer and Information Technology (CIT) has 12 laboratories. All labs are fully networked, and open for teaching, research, and development purposes only during university working hours, i.e. from 8:00 to 5:00. Students have limited access to computer labs as the labs are used for different purposes. Courses that require a lab component are assigned no more than four hours per week (JUST website, 2005).

\section{Impact of Technology on Higher Education}

Distance education today is generally used to accommodate those students who are unable to physically attend regular school to learn in a traditional learning environment. Invention and adoption of the Internet has a significant impact on distance education and traditional classroom based teaching.

Web-based learning (WBL) has become a major trend in teaching and learning. There are two major classes of these systems: synchronous and asynchronous (Kinshuk \& Young, 2003; Neubauer \& Lobel, 2003). Synchronous WBL systems are used to create virtual classroom environment where all students in a class are accessing the same information. Computer Supported Collaborative Work (CSCW) systems are synchronous in nature and designed to replace physical classrooms with the virtual ones (Litiu, 2003; Marsic, Dorohoceanu \& Tremaine, 2002). Most commonly available WBL systems are asynchronous in nature. In these systems, a web server hosts course contents and other teaching material. Learners have access to this material at anytime from anywhere using any web-browser (Linge, 2003).

Principe, Eulianno, and Lefebvre (2004) identify two basic levels in the utilization of computers in education: computer-based presentation, and computer-based instruction. They differ in the level of changes required in the teaching methodology. Use of multimedia presentations and web searching tools belong to the first category since they just make conventional classroom delivery more efficient and appealing; and they leave the teaching methodology largely unchanged. On the other hand, computer-based instructions imply a change in the traditional way of thinking about the discipline. It exploits the computer as added dimension to bridge the gap between the professor's knowledge, and how the students attain and retain the material.

Based on the mode of content delivery, a learning environment could be classified in one of the following three categories: (1) distance education completely online using web-based technologies, (2) traditional learning completely on-campus without web-based technologies and (3) Technology mediated learning where on-campus teaching is complemented with web-based teaching.

In technology mediated learning environment systems, the following factors contribute to effective online learning: using relevant and challenging assignments, having coordinated learning environment, adequate and timely feedback from instructors, developing rich environments for student-to-student interaction, flexibility in teaching and learning. In a good technology mediated 
learning system, students must be able to read, critically reflect, discuss, argue, generate and present new interpretations, share and exchange information ideas.

\section{Case Study}

To understand the impact of ICT on higher education in a Middle Eastern society, we conducted a survey at JUST and ZU. All surveyed students were enrolled in Computer Science/Information Systems courses. Participating students were enrolled in Information Technology, Computer Networks, Computer Architecture, and Operating Systems courses at JUST and a Database Systems course at ZU. In total 149 students, 73 female and 76 male, from JUST and 14 female students from ZU participated in this survey. It should be noted that the small size of ZU sample is due to the small sizes of classes in ZU. The survey was conducted by filling a hardcopy questionnaire. Table 3 shows the questionnaire and results.

It should be noted that in Table 3, the total of agree/disagree answers does not come to $100 \%$. For this reason, neutral responses were excluded.

In addition to ICT tools, we used online assessment tools to provide timely feedback. Unix and Oracle tools are also used that enable students to do their homework online remotely from home.

\section{Technology}

The effective use of technology in education depends on the quality of infrastructure and support available to students. At ZU, students have an excellent technology infrastructure where all students have their own laptops and have Internet connectivity from campus as well as from home. In Jordan, students have access to computing resources in relevant labs and availability of personal computers is much lower than students in UAE.

To learn about the quality of technology infrastructure, we asked students' opinion. 85\% students from ZU and 59\% students from JUST said that they did not have any problem in accessing Learning Management Systems (LMS) from home. 5\% from ZU and 14\% from JUST mentioned that they had problem in accessing the online resources.

\section{Communication}

Higher education in UAE is segregated based on gender while universities in Jordan have coeducation learning environment. Even outside university, culture and social values does not allow students to freely meet, have a discussion and exchange ideas in both countries. This factor affects communication skills and confidence level of students. How can the use of technology mitigate the impact of this factor to help students to improve their communication skills and confidence level?

We asked three questions to learn the impact of technology on students' communication with their fellow students, with their instructors, and overall communication skills. $56 \%$ of students from JUST and 71\% from ZU said that they use email to communicate with their fellow students. $26 \%$ from JUST and 14\% from ZU disagree on the usage of email. Response from female students at both universities was higher than male students' response. The difference in responses from ZU and JUST students could be explained by the quality and availability of infrastructure for educational technology available to students at both universities. 
Table 3 Impact of ICT on higher education: a comparative study between JUST and ZU

\begin{tabular}{|c|c|c|c|c|}
\hline \multirow{2}{*}{$\begin{array}{l}\text { Survey Question } \\
\text { Technology }\end{array}$} & \multicolumn{2}{|l|}{ Agree } & \multicolumn{2}{|c|}{ Disagree } \\
\hline & JUST & $\mathbf{Z U}$ & JUST & $\mathbf{Z U}$ \\
\hline I had no problem to access LMS from home. & $59 \%$ & $85 \%$ & $14 \%$ & $5 \%$ \\
\hline \multicolumn{5}{|l|}{ Communication } \\
\hline I used email to communicate with fellow students. & $56 \%$ & $71 \%$ & $26 \%$ & $14 \%$ \\
\hline I used email to communicate with my instructor in this class. & $38 \%$ & $71 \%$ & $31 \%$ & $14 \%$ \\
\hline I developed the ability to communicate clearly. & $59 \%$ & $78 \%$ & $9 \%$ & $0 \%$ \\
\hline \multicolumn{5}{|l|}{ Collaboration } \\
\hline $\begin{array}{l}\text { I checked the discussion board often to see what ques- } \\
\text { tions/answers people had. }\end{array}$ & $50 \%$ & $21 \%$ & $20 \%$ & $28 \%$ \\
\hline $\begin{array}{l}\text { Using communication tools such as discussion board improved } \\
\text { my productivity. }\end{array}$ & $57 \%$ & $42 \%$ & $13 \%$ & $55 \%$ \\
\hline I learned a lot from other students using the discussion board. & $51 \%$ & $42 \%$ & $23 \%$ & $21 \%$ \\
\hline $\begin{array}{l}\text { I was more interested in the subject by using the discussion } \\
\text { board. }\end{array}$ & $44 \%$ & $28 \%$ & $21 \%$ & $7 \%$ \\
\hline \multicolumn{5}{|l|}{ Technical Skill Development } \\
\hline Using online learning improved my technical skills. & $60 \%$ & $64 \%$ & $15 \%$ & $7 \%$ \\
\hline $\begin{array}{l}\text { The web resources mentioned on course web pages allowed me to } \\
\text { learn more about courses. }\end{array}$ & $54 \%$ & $74 \%$ & $15 \%$ & $6 \%$ \\
\hline \multicolumn{5}{|l|}{ Confidence Development } \\
\hline Using online learning allowed me to be more independent. & $52 \%$ & $64 \%$ & $19 \%$ & $28 \%$ \\
\hline $\begin{array}{l}\text { I felt more comfortable in posting my opinion on discussion } \\
\text { board rather than to speak up in class. }\end{array}$ & $58 \%$ & $64 \%$ & $20 \%$ & $7 \%$ \\
\hline $\begin{array}{l}\text { Using Online Learning Environment made me not dependent on } \\
\text { my teacher for help. }\end{array}$ & $50 \%$ & $57 \%$ & $25 \%$ & $7 \%$ \\
\hline $\begin{array}{l}\text { I became more confident in expressing my ideas using communi- } \\
\text { cation technologies such as email, chat, and discussion forum. }\end{array}$ & $75 \%$ & $71 \%$ & $7 \%$ & $0 \%$ \\
\hline \multicolumn{5}{|l|}{ Online Assessment } \\
\hline I regularly check my online grade book. & $77 \%$ & $99 \%$ & $9 \%$ & $1 \%$ \\
\hline $\begin{array}{l}\text { Online grade book kept me informed of my grades, and my ex- } \\
\text { pectation of my final grade in this course. }\end{array}$ & $79 \%$ & $99 \%$ & $8 \%$ & $0 \%$ \\
\hline $\begin{array}{l}\text { I liked the idea of having online exams, quizzes, class activities, } \\
\text { etc. }\end{array}$ & $59 \%$ & $50 \%$ & $21 \%$ & $43 \%$ \\
\hline
\end{tabular}


The second question was related to the use of email to communicate with class instructors. $38 \%$ from JUST and 71\% from ZU used email to communicate with their teachers while $31 \%$ from JUST and 14\% from ZU did not use email for communication with their teachers. UAE is a very conservative society while Jordan is comparatively liberal. One author who taught in UAE and in Jordan have observed that ZU students are usually very shy, and lack confidence in face-to-face communication. JUST students on the other hand, are less shy and more confident due to coeducation and frequent interaction with the members of the opposite gender. The difference in responses could also be explained based on the availability of technology and infrastructure. 59\% from JUST and 78\% from ZU students responded positively to the question "I developed the ability to communicate clearly using discussion forum”. Only 9\% from JUST responded negatively.

Overall, ZU students showed more appreciation of communication technology that helped them develop and improve their communication skills and overcome their shyness.

\section{Collaboration}

Class size at ZU has an average of 11 students per class and students are female only while class size at JUST has an average of 40 students per class and are usually large and students are both male and female. ZU students, once on-campus, cannot leave until the end of day. This policy provides lots of time on-campus with their class fellows and friends to communicate and collaborate. Environment in JUST University is very similar to any North American university campus. Students can come and go as they wish; this may result in limited face-to-face interaction and communication opportunities.

$50 \%$ from JUST and 21\% from ZU responded positively to the statement "I check the discussion board often to see what questions/answers people had". 19\% from JUST and 28\% from ZU disagree with this statement. 57\% from JUST and 42\% from ZU agree with "discussion board improved my group work productivity” statement. 13\% from JUST and 55\% from ZU disagree with this statement.

The discussion board helped students to learn from their peers. 51\% from JUST and $42 \%$ from ZU agree with it while $23 \%$ and $21 \%$ from JUST and ZU respectively disagree with it. $44 \%$ from JUST and $28 \%$ from ZU agree with "I was more interested in the subject because of discussion board " statement. 21\% from JUST and 7\% from ZU disagree with the statement.

JUST students used technology more effectively to collaborate than ZU students. These results are inline with our observations in the first paragraph of this section. ZU students did not use discussion forums effectively because they had enough time and opportunity to collaborate oncampus. JUST students have a more flexible and liberal environment. The larger class sizes and less time for face-to-face collaboration motivated JUST students to use discussion board to collaborate.

\section{Technical Skill Development}

Availability of online learning resources and computational tools could help students to improve their technical skills. Responses from the students are inline with our observations. This is more true in the case of ZU students living in a society with conservative cultural and social values.

$60 \%$ and $64 \%$ from JUST and ZU respectively agree to "online learning improved my technical skills" while $15 \%$ and $7 \%$ disagree with it. 54\% from JUST and 74\% from ZU responded positively to the statement "The web resources mentioned on course web pages allowed me to learn more about courses" and 15\% and 6\% disagree with this statement. 


\section{Confidence Development}

In the Middle Eastern culture, students often lack opportunity to freely meet, communicate, and collaborate. This results in shyness and lack of confidence to express opinion in front of members of the opposite gender. This is particularly true for female students. Technology allows students to meet, communicate, and collaborate in a virtual academic environment where most of the cultural and social limitations disappear. Interaction in the virtual world helps students to be more expressive and improve their confidence level. It also helps them to be more analytical and independent individuals.

52\% from JUST and 64\% from ZU agreed with "using online learning allowed me to be more independent” statement while $19 \%$ and 28\% disagreed with it. More students from ZU agreed than disagreed with this statement.

58\% from JUST and 64\% from ZU agreed with following statement: "I felt more comfortable in posting my opinion on discussion board rather than to speak up in class”. 20\% from JUST and $7 \%$ from ZU disagree with it. Technology helped students to overcome their shyness and gave them confidence to present their opinion and views.

$75 \%$ and $71 \%$ of students from JUST and ZU respectively agreed to "I became more confident in expressing my ideas using communication technologies such as email, chat, and discussion forum.” statement.

\section{Online Assessment}

Students in both universities appreciated the posting of their grades online. 77\% from JUST and 99\% from ZU indicated they regularly check their online grade book. Almost the same percentage of 79\% from JUST, and 99\% from ZU agreed with the following statement "Online grade book kept me informed of my grades, and my expectation of my final grade in this course". The higher percentage of ZU compared to JUST students who used the online grade book could be explained by the availability of infrastructure for educational technology.

Students' opinion on having online exams, quizzes, and class activities were 59\% from JUST compared to $50 \%$ from ZU. 21\% from JUST and 43\% from ZU indicated they liked to have offline exams.

\section{Social Aspect}

It was very interesting to learn that all students felt that the use of online learning environment removed the cultural and social limitations imposed by restrictive learning environment at ZU and JUST (e.g. opportunities to discuss with friends and to access resources after campus hours).

The use of technology helped ZU students who live in a conservative Arab society to overcome family restrictions and to collaborate with their peers after campus hours, which was not possible without technology. Typical responses and comments from ZU are the following:

“Some students can’t get together because they are living far away from each other or their families wouldn't allow them to go out by themselves. Using technology allow us to access materials from anywhere anytime”

"When students use technology they will not be limited by place (only campus) and time (during 5 days a week) to learn or study for this course. For example, on last Oracle exam even though one of the questions was difficult to answer but I used Unix to talk with other student on class. Also I looked for the power points on Blackboard, and searched on the internet for similar exercise" 
"Sometimes we do not have the time to sit with friends after campus hours. Most of my friends live far away from our house. Using online communication overcomes this problem because most of the students can access the internet anytime”

"Some students" families do not allow their daughters to go out evening even to go to a general library. Online teaching environment helps us overcome these limitations and to do the work at home”

The use of technology helped JUST students who live in a relatively liberal Arab country to be more socially active and to express their ideas effectively and more openly with others. Typical responses and comments from JUST include:

"Technology helped us to be more confident in ourselves. It helped us to study alone and without asking the teacher all the time"

"It helped me to communicate with people outside the university and talk with them about their experiences"

"According to me as a girl, it is more comfortable to access course materials from home and use Internet at home even if it was late rather than going to Internet Cafe"

\section{Conclusions}

Cultural and social values in Middle Eastern countries are usually based on gender segregation. This factor results in a lack of interaction, lack of confidence in communication and a lack of opportunity to meet and exchange ideas with members of the opposite gender. Society in general has stricter rules of interaction and communication for females. We think that technology could help overcome these cultural limitations by providing alternate means of interaction, communication, and collaboration without changing the existing social and cultural norms.

The results of our case study reassured our observations that studying in a technology mediated learning environment could improve motivation and the confidence level of students. Some of the important findings from the case study are: (a) use of technology improved students communication skills, (b) use of technology allowed students to be more independent, (c) it also improved motivation and confidence levels of students, and (d) allowed students to express their feelings and ideas more openly with others. ZU students in a conservative society used technology to develop their communication skills, gain confidence, and overcome their shyness. They did not use collaboration tools effectively. JUST students in a moderately liberal country used technology to communicate with their peers and relied heavily on collaboration technology.

\section{References}

Galpin, V. (2002). Women in computers around the world. ACM SIGCSE Bulletin, 34(2), 94 - 100.

Hodges, C. (2004, Winter). Designing to motivate: Motivational techniques to incorporate in e-learning experience. The Journal of Interactive Online Learning, 2(3).

Information in the UAE, (2005). Retrieved March 23, 2005 from http://homepages.ius.edu/BPEKINPA/web4.htm

Jordan University of Science and Technology web site. (2005). Retrieved April 20, 2005 from http://www.just.edu.jo

Kinshuk \& Young, A. (2003, April). Web-based asynchronous synchronous environment for online learning. Journal of the USDLA.

Kurzban, S. (1982). Societies' adaptation to computing. ACM SIGCAS Computers and Society, 12(2), Spring, 14-20. 
Linge, R. (2003). The good, the bad, and the ridiculous: Putting a course online with Blackboard. The Consortium for Computing in Small Colleges.

Litiu, R. \& Prakash, A. (2000). Developing adaptive groupware applications using a mobile component framework. Proceedings of the ACM 2000 Conference on Computer Supported Cooperative Work (CSCW 2000), Philadelphia, PA, USA.

Marsic, A. Krebs, B. Dorohonceanu, \& Tremaine, M. (2002). Designing and examining PC to Palm collaboration. Proceedings of the 35th Annual Hawaii International Conference on System Sciences (HICSS'02).

Muhlhauser, M. \& Trompler, C. (2002). Learning in the digital age: Paving a smooth path with digital lecture halls. Proceedings of HiCSS 35th Hawaii Intl. Conference, Waikola, HI, Jan. 7-12, 2001, IEEE CS press, Los Alamitos, CA, pp. 352-361.

Neubauer, M. \& Lobel, M. (2003). The learning by doing eClassroom. Journal of the USDLA, 17(2), 5-17.

Principe, J., Eulianno, N. \& Lefebvre, C. (2004). An interactive learning environment for adaptive systems instruction. Retrieved April 20, 2005 from http://www.cnel.ufl.edu/files/1023120351.pdf

Saunders, B. \& Quirke, P. (2002). Let my laptop lead the way: A Middle Eastern study. Educational Technology and Society, 5(1). ISSN 1436-4522.

Smith, M. \& Winking-Diaz, A. (2004). Increasing students' interactivity in an online course. The Journal of Interactive Online Learning, 2(3).

Straub, D. (1994). The effect of culture on IT diffusion: E-mail and fax in Japan and the US. Information Systems Research, 5(1), 23-47.

Straub, D., Loch, K., Evaristo, J. R., Karahanna, E., \& Srite, M. (2002). Toward a theory based measurement of culture. Journal of Global Information Management. Vol. 10, No. 1, 2002, pp. 13-23

Technology and Equity: Case studies, (2005). Retrieved April 2005 from http://projects.aed.org/techequity/index.html

UNDP Arab Human Development Report, (2003). Retrieved March 29, 2005 from http://www.undp.org/

United Nations Development Programme (UNDP): POGAR, (2005). Retrieved March 23, 2005 from http://www.undp-pogar.org/countries/

Walton, M., \& Vukovic, V. (2003). Cultures, literacy, and the web: Dimensions of information "scent". Interactions SPECIAL ISSUE: HCI in the developing world, 10(2), 64-71.

Women in the United Arab Emirates, (2005). Retrieved March 23, 2005 from http://www.findarticles.com/p/articles/mi_m2242/is_1651_283/ai_107897410

Wong, Y., Shi, Y., \& Wilson, D. (2004). Impact of computers on society and organization: Experience, gender composition, social presence, decision process satisfaction and group performance. ACM International Conference Proceedings Series; 58 : Proceedings of the Winter International Symposium on Information and Communication Technologies WISICT '04. pp. 1- 10.

World Economic Forum, (2005). Jordan educational ICT pilot initiative. Retrieved April 13, 2005 from http://www.weforum.org/pdf/DigitalDivide/Jordan_Country_Report_100902.pdf

Zayed University web site, (2005). Retrieved April 20, 2005 from http://www.zu.ac.ae 


\section{Biographies}

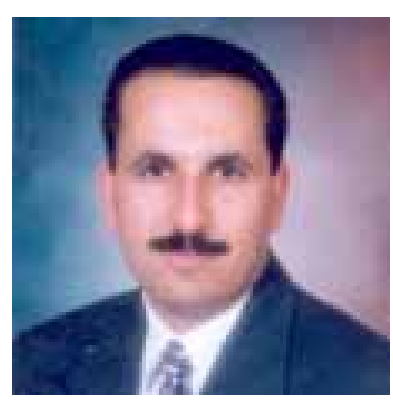

Abdallah Tubaishat is an assistant professor in the College of Information Systems at Zayed University, United Arab Emirates. He received his $\mathrm{PhD}$ degree in Software engineering from the from Illinois Institute of Technology, USA in 1994. Dr. Tubaishat has around eleven Years of experience in teaching and research. His research interests include e-learning, and software engineering. He has published a book with others entitled "Computer Skills", and has around eighteen Journal and conference publications.

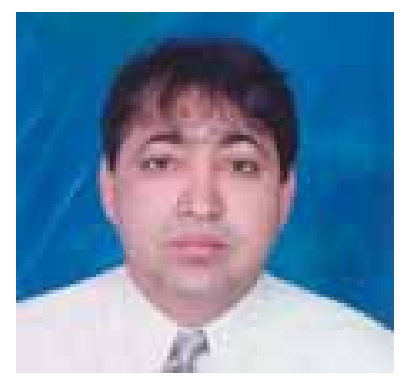

Arif Bhatti is an assistant professor at GIFT University, Pakistan. He received his $\mathrm{PhD}$ degree in Computer Science from the Boston University, USA in 1997. He joined the industry as senior software engineer and worked on several projects related to the parallel computing for business and web applications for mobile users. He is interested in applied research and his research interests include parallel computing, wireless computing, and distributed online learning technologies. He is a member of the ACM.

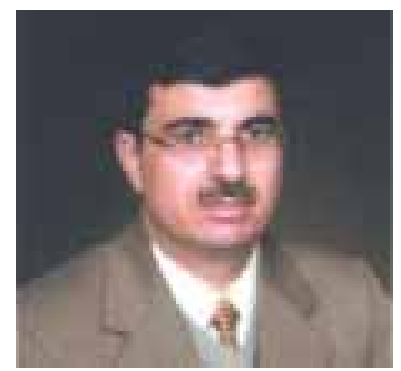

Eyas El-Qawasmeh is an assistant professor in the department of the Computer Science at Jordan University of Science and Technology, Jordan. He received his PhD degree from George Washington University, USA in 1997. In 2001, he joined George Washington University as visiting researcher through a Fulbright Commission grant. In 2001, he won Hijjawi research prize for Computer Science (best computer researcher in 2001, Jordan and Palestine). His areas of interest include multimedia databases, information retrieval, and object-oriented. He is a member of the ACM and IEEE. 